\title{
Divalent magnesium restores cytoskeletal storage lesions in cold-stored platelet concentrates
}

Konstanze Aurich ( $\square$ konstanze.aurich@med.uni-greifswald.de)

Universitätsmedizin Greifswald

Jan Wesche

Universitätsmedizin Greifswald

Martin Ulbricht

Universitätsmedizin Greifswald

Oliver Otto

Universität Greifswald

Andreas Greinacher

Universitätsmedizin Greifswald

Raghavendra Palankar

Universitätsmedizin Greifswald

\section{Research Article}

Keywords: refrigeration blood platelets, magnesium, cytoskeleton

Posted Date: July 22nd, 2021

DOI: https://doi.org/10.21203/rs.3.rs-667016/v2

License: (c) (i) This work is licensed under a Creative Commons Attribution 4.0 International License.

Read Full License

Version of Record: A version of this preprint was published at Scientific Reports on April 14th, 2022. See the published version at https://doi.org/10.1038/s41598-022-10231-x. 


\section{Abstract}

Cold storage of platelet concentrates (PC) has become attractive due to the reduced risk of bacterial proliferation, but in vivo circulation time of cold-stored platelets is reduced. $\mathrm{Ca}^{2+}$ release from storage organelles and higher activity of $\mathrm{Ca}^{2+}$ pumps at temperatures $<15^{\circ} \mathrm{C}$ triggers cytoskeleton changes. This is suppressed by $\mathrm{Mg}^{2+}$ addition, avoiding a shift in $\mathrm{Ca}^{2+}$ hemostasis and cytoskeletal alterations. We report on the impact of 2-10 $\mathrm{mM} \mathrm{Mg}^{2+}$ addition on cytoskeleton alterations of platelets from PC stored at room temperature (RT) or $4^{\circ} \mathrm{C}$ in additive solution (PAS), 30\% plasma. Deformation of platelets was assessed by real-time deformability cytometry (RT-DC), a method for biomechanical cell characterization. Deformation was strongly affected by storage at $4^{\circ} \mathrm{C}$ and preserved by $\mathrm{Mg}^{2+}$ addition $\geq 4 \mathrm{mM} \mathrm{Mg}^{2+}$ (mean $\pm \mathrm{SD}$ of median deformation $4^{\circ} \mathrm{C}$ vs. $4^{\circ} \mathrm{C}+10 \mathrm{mM} \mathrm{Mg}^{2+} 0.073 \pm 0.021$ vs. $0.118 \pm 0.023, p<0.01 ; \mathrm{n}$ $=6$, day 7). These results were confirmed by immunofluorescence microscopy, showing that $\mathrm{Mg}^{2+} \geq$ $4 \mathrm{mM}$ prevents $4^{\circ} \mathrm{C}$ storage induced cytoskeletal structure lesion. Standard in vitro platelet function tests showed minor differences between RT and cold-stored platelets. Hypotonic shock response was reduced in cold-stored platelets $(45.65 \pm 11.59 \%$ vs. RT stored platelets $56.38 \pm 29.36 ; p=0.042)$ but normal at $4^{\circ} \mathrm{C}$ $+10 \mathrm{mM} \mathrm{Mg}^{2+}(55.22 \pm 11.16 \%$, all $\mathrm{n}=6$, day 1$)$. CD62P expression and platelet aggregation response were similar between RT and $4{ }^{\circ} \mathrm{C}$ stored platelets, with minor changes in the presence of higher $\mathrm{Mg}^{2+}$ concentrations. In conclusion, increasing $\mathrm{Mg}^{2+}$ up to $10 \mathrm{mM}$ in PAS counteracts $4^{\circ} \mathrm{C}$ storage lesions in platelets, maintains platelet cytoskeletal integrity and biomechanical properties comparable to RT stored platelets.

\section{Introduction}

Platelet transfusions are a mainstay of treatment in patients with hypoproliferative thrombocytopenia or major hemorrhage. ${ }^{1}$ Platelet concentrates are stored at room temperature (RT), which preserves in vivo platelet survival and recovery. However, this increases the risk for bacterial growth. Cold storage of platelet concentrates at $4{ }^{\circ} \mathrm{C}$ reduces the risk of bacterial proliferation. ${ }^{1}$ Recent studies have shown that cold storage maintains and even improves some in-vitro platelet functions in comparison to storage at RT. $^{2,3}$ However, the in vivo circulation time/life span of cold-stored platelets is considerably reduced. ${ }^{4,5}$ Loss of glycoprotein Iba (GPIba) due to increased metalloproteinase ADAM17 activity and glycan modifications are thought to play a role. ${ }^{6,7}$ Cleavage of terminal sialic acid and clustering of exposed $\beta-\mathrm{N}$ acetyglucosamines of $\mathrm{GPIba}^{5}$ exposes $\beta$-galactose on the platelet surface. This is recognized by the Ashwell Morell receptor of hepatocytes or liver macrophages, which then phagocytose platelets. ${ }^{8,9}$ Furthermore, temperatures below $15^{\circ} \mathrm{C}$ induce divalent calcium $\left(\mathrm{Ca}^{2+}\right)$ release from platelet storage organelles, and higher activity of $\mathrm{Ca}^{2+}$ pumps both result in increased intracellular $\mathrm{Ca}^{2+}{ }^{2}$ This triggers signaling cascades leading to cytoskeleton rearrangements and platelet shape change, ${ }^{10}$ thought to mainly occur as a result of increased activity of the $\mathrm{Ca}^{2+}$ dependent cysteine protease calpain, which

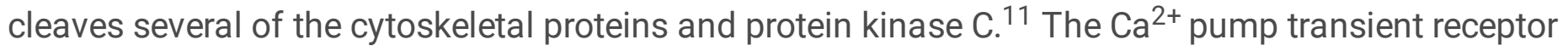
potential melastatin-like 7 channel (TRPM7) also regulates magnesium $\left(\mathrm{Mg}^{2+}\right)$ influx into platelets. $\mathrm{Mg}^{2+}$ 
dependent TRPM7 kinase phosphorylates non-muscle myosin IIA (NMMIIA) that mediates the contractility of the actin cytoskeleton. ${ }^{12-14} \mathrm{Mg}^{2+}$ reverses cold-induced intracellular $\mathrm{Ca}^{2+}$ increase and inhibits consecutive cytoskeletal alterations. ${ }^{12}$ Cytoskeletal integrity thus may serve as a sensitive readout for cold storage induced platelet cytoskeleton lesions. To assess cytoskeleton-dependent biomechanical properties of platelets, several biophysical methods are available. ${ }^{15}$ We used real-time deformability cytometry (RT-DC), for mechanical characterization of platelets with high throughput of up to 1,000 cells per second to evaluate the impact of cold storage on platelet cytoskeleton. ${ }^{16-19}$

Here, we report that the addition of up to $10 \mathrm{mM} \mathrm{Mg}^{2+}$ to platelets stored in platelet additive solution (PAS) plus 30\% plasma prevents cytoskeleton alterations during long-term cold storage at $4{ }^{\circ} \mathrm{C}$, while maintaining platelet function. In addition, we present a new ex vivo quality control approach to assess platelet concentrates in a whole blood matrix.

\section{Results}

\section{Leukocyte and platelet depleted whole blood as a matrix to assess the function of platelet concentrates}

We developed a method, which allows ex vivo quality control of PC under whole blood conditions. Leukocytes and platelets are considerably reduced by inline filtration of whole blood (Table 1). This provides a near platelet-free whole blood matrix. This platelet-depleted whole blood can be spiked with platelets of interest to assess platelet function in the presence of red cells and plasma proteins.

\section{Magnesium does not adversely affect platelet function in vitro}

We prepared PC in 70\% SSP+ storage buffer (which contains $2 \mathrm{mM} \mathrm{Mg}^{2+}$ ) plus $30 \%$ plasma and added 2, 4,6 , and $8 \mathrm{mM} \mathrm{Mg}^{2+}$ before storage (final $\mathrm{Mg}^{2+}$ concentrations $2,4,6,8,10 \mathrm{mM}$ ). The additional magnesium did not exceed the physiological tonicity as it results in a maximum osmolarity of 319 mOsm/L (Supplementary Figure S2).

Hypotonic shock response did not differ substantially between the different storage conditions or $\mathrm{Mg}^{2+}$ concentrations (Figure $1 \mathrm{~A}$ ). Also, increasing $\mathrm{Mg}^{2+}$ concentrations did not alter platelet reactivity to TRAP6, as measured by CD62P expression, after $4{ }^{\circ} \mathrm{C}$ storage (Figure 1B), which was reduced in comparison to RT stored platelets at day 1 : fold change RT $\left(2 \mathrm{mM} \mathrm{Mg}^{2+}\right) 9.8 \pm 2.4$ vs $4{ }^{\circ} \mathrm{C}\left(2 \mathrm{mM} \mathrm{Mg}^{2+}\right) 6.1 \pm 1.3$ $(p<0.001)$. Thereafter the differences were minor between both storage conditions.

In contrast to TRAP-6, platelet response to collagen $(8 \mu \mathrm{g} / \mathrm{mL})$ was better preserved in cold stored platelets after 4 and 7 days of storage (day 7: RT $\left(2 \mathrm{mM} \mathrm{Mg}^{2+}\right)$ maximum aggregation $22.54 \pm 9.61 \%$ vs 4 $\left.{ }^{\circ} \mathrm{C}\left(2 \mathrm{mM} \mathrm{Mg}^{2+}\right) 45.96 \pm 19.24 \%, \mathrm{n}=6, p<0.001\right)$, especially at higher magnesium concentrations after 7 days of storage $\left(4^{\circ} \mathrm{C}+10 \mathrm{mM} \mathrm{Mg}^{2+}\right.$ : maximum aggregation $77.97 \pm 5.87 \%, \mathrm{n}=6, p<0.001$, Figure $\left.1 \mathrm{C}\right)$. 
Spiking leukocyte and platelet depleted whole blood with platelets from differently stored PC and rewarming them at $37^{\circ} \mathrm{C}$ for 1 hour did not substantially change the aggregation response to collagen compared to platelets measured in PRP (Figure 1D).

\section{Magnesium prevents platelet cytoskeleton storage lesions}

The deformation to area scatterplots by RT-DC showed an apparent decrease in deformation and cell area of platelets stored at $4{ }^{\circ} \mathrm{C}$ (Figure $2 \mathrm{~A}$ ). This was primarily prevented by increasing concentrations of $\mathrm{Mg}^{2+}$. For all six PC tested, median deformation ( $n \geq 20,000$ single platelets) decreased due to storage at $4{ }^{\circ} \mathrm{C}$ and generally increased with $\mathrm{Mg}^{2+}$ addition (Figure $2 \mathrm{~B}$ ). This effect was particularly pronounced on storage day 7.

Next, we assessed the integrity and reorganization of the marginal band tubulin ring. After storage at RT the tubulin ring is visible, both in the microscopic image and by the separated peaks of the crosssectional fluorescence signals (Figure $3 \mathrm{~A}$ ). Storing platelets at $4{ }^{\circ} \mathrm{C}$ induces disorganization of tubulin and distribution of the fluorescence signal throughout the cell (Figure 3A bottom, Figure 3B top left). Rewarming of platelets from cold-stored PCs in platelet-depleted whole blood has no consequences on the disorganization of the tubulin ring at $4{ }^{\circ} \mathrm{C}$ (figure $3 \mathrm{~B}$ top right). Additional $\mathrm{Mg}^{2+}$ prevented tubulin depolymerization with the ,most substantial effects at 8 and $10 \mathrm{mM} \mathrm{Mg}^{2+}$ (Figure $3 \mathrm{~B}$ bottom).

\section{Magnesium addition does not impair desialylation of platelets during cold storage}

Cold storage initialized desialylation of platelet surface, resulting in increased phagocytosis of platelets by hepatocytes via the Ashwell-Morell receptor. We determined the binding of two different lectins, Erythrina cristagalli lectin (ECL) and Ricinus communis lectin agglutinin (RCA), to desialylated galactose and $\beta$-N-acetyl glucosamine (GlcNAc) residues on the surface of RT and cold-stored platelets with or without additional magnesium. Lectin binding is reduced due to cold storage but did not change with increasing magnesium concentration (Figure 4).

\section{Discussion}

In this study, we provide evidence that increasing the $\mathrm{Mg}^{2+}$ concentration of the storage medium up to 10 $\mathrm{mM}$ prevents platelet cytoskeleton storage lesions during storage at $4{ }^{\circ} \mathrm{C}$. Otherwise, platelets storage at 4 ${ }^{\circ} \mathrm{C}$ leads to shape change, spherocytosis, and decreased mean platelet volume. ${ }^{4,10}$ Recently, it has been shown that the platelet shape change, which is driven by the cytoskeleton, is mainly caused by two processes: (i) increased activity of calpain, a $\mathrm{Ca}^{2+}$ dependent cysteine protease, which cleaves platelet actin leading to rigid, stiff cells ${ }^{20}$ and (ii) upregulated NMMIIA activity, a motor protein mediating contractility of the platelet actin cytoskeleton. ${ }^{12}$ During cold storage, intracellular $\mathrm{Ca}^{2+}$ increases due to active transport or passive $\mathrm{Ca}^{2+}$ leakage from platelet organelles and reduced $\mathrm{Ca}^{2+}$ pump activity leading to a slow accumulation of $\mathrm{Ca}^{2+} .{ }^{10}$ Subsequently, store-operated $\mathrm{Ca}^{2+}$ entry (SOCE) and receptor-operated $\mathrm{Ca}^{2+}$ entry regulate further $\mathrm{Ca}^{2+}$ increase, which regulates platelet integrin allb $\beta 3$ activation by calpain 
and platelet degranulation. ${ }^{11,21,22}$ TRPM7 channel is the key channel controlling $\mathrm{Mg}^{2+}$ and $\mathrm{Ca}^{2+}$ exchange in platelets. ${ }^{12}$ TRPM 7 kinase activity is mediated by $\mathrm{Mg}^{2+}$ and directly affects intracellular $\mathrm{Ca}^{2+}$ concentration via SOCE, phospholipase $\mathrm{C}$ and $\mathrm{\gamma} 2 .{ }^{13} \mathrm{As}$ a consequence $\mathrm{Mg}^{2+}$ supplementation counteracts intracellular $\mathrm{Ca}^{2+}$ increase, which prevents calpain activation. Furthermore, NMMIIA activity can be inhibited by enhanced intracellular $\mathrm{Mg}^{2+}$ concentrations, which increases adenine diphosphate (ADP) release, followed by induction of NMMIIA C-terminus phosphorylation. ${ }^{20}$ This interplay between $\mathrm{Ca}^{2+}$ and $\mathrm{Mg}^{2+}$ is key of our concept to prevent alterations of the platelet cytoskeleton during cold storage by $\mathrm{Mg}^{2+}$ supplementation.

We also demonstrate that cold-induced cytoskeletal disorganization of platelets during storage at $4{ }^{\circ} \mathrm{C}$ is prevented by the addition of $\mathrm{Mg}^{2+}$ into the storage media. This we show by two independent methods: First by confocal laser scanning microscopy of platelet cytoskeletal proteins. However, immunofluorescence studies of platelets are low throughput and are at risk of a selection bias. Secondly by RT-DC, which we have recently introduced as a high throughput method to assess platelet biomechanics. ${ }^{23}$ RT-DC allows measuring thousands of platelets within minutes and is the first method providing an unbiased, comprehensive analysis of the biomechanics of platelets in platelet concentrates. Consistent with our immunofluorescent studies, RT-DC shows preservation of platelet deformation at $4{ }^{\circ} \mathrm{C}$ by the addition of $\mathrm{Mg}^{2+}$.

The main reason for the reduced platelet survival after cold storage might be desialylation of platelet glycoproteins resulting in increased phagocytosis by hepatocytes. We showed that increased $\mathrm{Mg}^{2+}$ addition does not reduce desialylation during cold storage of platelets in vitro. It is more likely that magnesium affects platelet survival by other mechanisms. The exact molecular mechanisms of how increased $\mathrm{Mg}^{2+}$ concentrations prevent changes of the platelet cytoskeleton are still only partly understood. One proposed mechanism is by inhibiting the cold-induced increase in intracellular $\mathrm{Ca}^{2+}$ concentrations without activating calpain. Another potential mechanism might be the reduction of intracellular $\mathrm{Ca}^{2+}$ release after activation of GPIb. The binding of von Willebrand factor (vWF) to a mechanosensitive domain of GP Iba triggers outside-in mechanotransduction signals in platelets, leading to intracellular $\mathrm{Ca}^{2+}$ release. ${ }^{24}$ Platelet concentrates have to be stored under agitation that platelets can move along the gas permeable plastic membrane of the storage bag. This allows the release of $\mathrm{CO}_{2}$ and uptake of $\mathrm{O}_{2}$. Likely the shear stress on the plastic membrane of the platelet concentrate storage bag unfolds vWF, which then binds GPIb mediating mechano-signaling, which finally leads to an increase in plasmatic $\mathrm{Ca}^{2+}$ concentrations. In line with this hypothesis, blocking the vWF-GPIba interaction by the peptide OS1 that blocks VWF binding to GPIba, resulted in increased post-transfusion recovery and survival of cold-stored platelets in mice. ${ }^{25}$

The currently used PAS SSP+ already contains $2 \mathrm{mM} \mathrm{Mg}^{2+}$. However, this concentration is not sufficient to prevent platelet storage lesions of the cytoskeleton. Our study shows that at least $\mathrm{Mg}^{2+}$ concentrations of $4 \mathrm{mM}$ are required to prevent platelet cytoskeleton storage lesions. Increasing ion concentrations raise 
the issue of changing the osmolarity of the storage solution. However, at $10 \mathrm{mM} \mathrm{Mg}^{2+} \mathrm{PAS}$, osmolarity increased only by $4 \%$, which is obviously well tolerated by platelets.

These concentrations are safe for the transfusion recipient. $\mathrm{Mg}^{2+}$ had been used extensively in obstetrics to control uterus contractions in concentrations up to $100 \mathrm{mmol}$ given intravenously. This is 40 -fold more than the $\mathrm{Mg}^{2+}$ dose given with a standard platelet concentrate. ${ }^{26}$ Even the high concentrations given in obstetric patients have shown to be safe regarding the cardiovascular system and liver disease. ${ }^{27-29}$

$\mathrm{Mg}^{2+}$ addition to platelet storage buffers has also been tested by others. Storing platelets in PAS containing up to $6 \mathrm{mM} \mathrm{Mg}^{2+}$ resulted in relatively minor changes on platelet metabolism (platelet count, $\mathrm{pH}$, lactate concentration). ${ }^{30}$ Storage of platelets in PAS containing up to $2 \mathrm{mM} \mathrm{Mg}^{2+}$ resulted in higher platelet quality and reduced cytokine release in vitro. ${ }^{31,32}$ A storage medium containing adenine, lidocaine, and $7 \mathrm{mM} \mathrm{Mg}^{2+}$ in PAS or plasma stored platelets preserved the aggregation response to ADP and TRAP- 6 at RT and $4{ }^{\circ} \mathrm{C}$ storage. ${ }^{33}$ In agreement with these findings, we observed that the aggregation response of platelets to collagen in PAS+ with $30 \%$ plasma was better preserved during storage of 7 days at $4{ }^{\circ} \mathrm{C}$ in the presence of increasing concentrations of $\mathrm{Mg}^{2+}$.

Recently, we observed that cold storage also triggers phosphatidylserine exposure indicating platelet apoptosis. ${ }^{2}$ Interestingly, Getz et al. observed that platelet apoptosis is reduced in citrate-free PAS. ${ }^{34}$ Our results suggest that this might be due to increasing available $\mathrm{Mg}^{2+}$ by the absence of chelating agent citrate.

Cold storage of platelets also triggers an increased activation of metalloproteinases such as ADAMTS17, which in turn cleaves sialic acid from and GPIb leading to enhanced recognition and clearance of platelets by hepatic macrophages. ADAMTS17 inhibitors such as GM6001 block this effect in vitro. ${ }^{35}$ During platelet storage also caspase enzymes are expressed and activated. They cleave numerous cellular proteins leading to cell death. Accordingly, it has been shown that Caspase- 3 inhibitors block apoptosis during storage. ${ }^{36}$

In view of these other effects of cold storage induced platelet lesions, likely a combination of different approaches is required to preserve platelet in vivo recovery, survival, and function after cold storage of platelet concentrates.

Here we have shown that increasing $\mathrm{Mg}^{2+}$ concentrations to up to $10 \mathrm{mM}$ is one important and easy to apply approach towards preventing cold-induced cytoskeleton storage lesions in platelets.

\section{Methods}

\section{Platelet concentrates}


Whole blood was collected from healthy donors according to the German guidelines for hemotherapy with written informed consent. The study was approved by the ethical board of the Universitätsmedizin Greifswald, Germany. Pooled platelet concentrates from whole blood buffy coats were produced according to the standard method for producing therapeutic platelet concentrates. In brief, after centrifugation $(4000 \mathrm{~g}, 10 \mathrm{~min}$ ), whole blood in citrate phosphate dextrose solution (CPD, Macopharma, France) was separated into red cell concentrate, plasma, and buffy coat. Buffy coats of 4 blood group identical donations were pooled, and $250 \mathrm{~mL}$ additive solution SSP+ (Macopharma) was added. SSP+ itself contains $2 \mathrm{mM}$ magnesium. By centrifugation ( $720 \mathrm{~g}, 15 \mathrm{~min})$, platelets were separated from residual red blood cells and leukocyte depleted (LEUCOFLEX® LXT Filter, Macopharma). PC bags were split into six bags (gas permeable bags, Macopharma) and stored under agitation at RT or $4{ }^{\circ} \mathrm{C}$ for 7 days.

\section{Platelet concentrate storage}

Magnesium sulfate solution (Inresa Arzneimittel GmbH, Germany) was added to four of the six bags in increasing concentrations (Table 2). PC was stored under agitation on an orbital shaker (LPR1, Melco Engineering Corp., USA). Sampling took place on day 0 (production day), day 1, day 4 and day 7.

\section{In vitro platelet function testing}

The ability of platelets to respond to a hypotonic environment was determined as hypotonic shock response (HSR) by light transmission aggregometry (LTA). ${ }^{37}$ Platelets were exposed to distilled water or $0.9 \% \mathrm{w} / \mathrm{v}$ sodium chloride solution as a control. Due to the osmotic gradient, the water diffuses into the platelets, which leads to their swelling. As a result of swelling, the refractive index of platelets increases, resulting in a decrease in light transmission. The percentage of HSR was calculated as (T2-T3)/(T2$\mathrm{T} 1) \times 100$, with $\mathrm{T} 1=$ transmission of platelet suspension in sodium chloride; $\mathrm{T} 2=$ transmission of platelets in distilled water; $\mathrm{T3}=$ "plateau" transmission value after $4 \mathrm{~min}$ of platelets incubated in distilled water.

Platelet activation was determined by $\mathrm{CD} 62 \mathrm{P}$ expression before and after the addition of thrombin receptor activating peptide 6 (TRAP-6). $3 \times 10^{8} / \mathrm{mL}$ platelets were incubated for 15 min at $37^{\circ} \mathrm{C}$ with 20 $\mu \mathrm{M}$ TRAP-6 (Hart Biologicals, UK) or PBS buffer (w/o Ca ${ }^{2+}, \mathrm{Mg}^{2+} ; \mathrm{pH} 7.2$ ) as the negative control, fixed 20 min with $0.5 \%$ paraformaldehyde (Morphisto Laborchemikalien, Germany) and washed twice (2 mL PBS; $650 \mathrm{~g}, 7 \mathrm{~min}, \mathrm{RT}$ ). The pellet was resuspended in $500 \mu \mathrm{L}$ PBS and analyzed by flow cytometry (FC500, Beckman Coulter, USA). Platelets were gated using a mouse-anti-human CD41-PeCy5 (clone P2, Beckman Coulter) labeled monoclonal antibody. The increase of CD62P exposure on CD41-positive events was determined using CD62P-FITC (clone CLBThromb/6, Beckman Coulter, USA). The mean fluorescence intensity of TRAP- 6 activated platelets is given as fold increase in comparison to the respective buffer controls.

Platelet aggregation was analyzed over $7 \mathrm{~min}$ at $37^{\circ} \mathrm{C}$ in a 4-channel-aggregometer (DiaSys, Germany) after the addition of $8 \mu \mathrm{g} / \mathrm{mL}$ collagen (Mölab, Germany). 


\section{Whole blood as a matrix for ex vivo quality control of platelet concentrates}

To simulate in vivo conditions, we prepared platelet-depleted whole blood (dWB). Whole blood was collected from a healthy donor according to the German guidelines for hemotherapy, using a bag system containing citrate-phosphate-derivative with adenine (CPDA) solution for anticoagulation. Directly after donation, whole blood was leukocyte and platelet depleted by a LEUCOFLEX® LXT leukocyte depletion filter, which removes $99.999 \%$ of leukocytes and platelets (Macopharma, France). Cell counts were determined before and after filtration by an automated blood cell analyzer (Sysmex XP300, Sysmex Deutschland $\mathrm{GmbH}$, Germany). Depleted whole blood was stored at $4{ }^{\circ} \mathrm{C}$ until use. Platelets stored at $4{ }^{\circ} \mathrm{C}$ at different $\mathrm{Mg}^{2+}$ concentrations were either analyzed directly in platelet storage buffer SSP+ or spiked into depleted whole blood to achieve a final platelet concentration of $300,000 / \mu \mathrm{L}$ and rewarmed at $37^{\circ} \mathrm{C}$ for one hour before analyses. For aggregometry studies, whole blood was centrifuged at $120 \mathrm{~g}$ for $20 \mathrm{~min}$ to obtain PRP.

\section{Biomechanical platelet characterization}

RT-DC is a method for the biomechanical characterization of cells with throughput rates of up to 1,000 per second (Supplementary figure S1). ${ }^{23}$ In brief, platelets are pumped at flow rates of $0.006 \mathrm{~mL} / \mathrm{s}$ from a reservoir through a narrow channel on a chip assembled on the AcCellerator system (Zellmechanik Dresden). The microfluidic chip consists of a constriction of $15 \mathrm{~mm} \times 15 \mathrm{~mm}$ cross-section with a length of $300 \mathrm{~mm}$ and is connected to a syringe pump (NemeSys, Cetoni, Germany). Upon entering the channel and during the passage, the cells are subjected to both hydrodynamic shear forces and different pressure gradients. The deformation of platelets caused by these external forces are recorded by a high-speed camera. The individual images are then analyzed with an evaluation algorithm (ShapeOut, version 0.8.6, Zellmechanik Dresden) for the deformation of the individual platelet (Supplementary Figure S1). ${ }^{17}$ Samples were taken on days 1, 4, and 7 after PC production. For RT-DC $50 \mathrm{~mL}$ of platelets in $\mathrm{SSP}+$ /plasma were diluted in Carrier B (Zellmechanik Dresden; $0.6 \%(\mathrm{w} / \mathrm{v})$ methylcellulose in PBS, without $\mathrm{Ca}^{2+}$ and $\mathrm{Mg}^{2+}$ ) to a final concentration of approximately $1 \times 10^{7} / \mathrm{mL}$. Calculations are performed at different flow rates representing different experimental conditions.

\section{Analysis of cytoskeleton proteins by immunofluorescence microscopy}

Platelets from PC of all 6 storage conditions were adjusted to a platelet count of 50,000 platelets/ $\mu \mathrm{L}$ each with $2 \%$ paraformaldehyde in PBS ( $\left.\mathrm{w} / \mathrm{o} \mathrm{Ca}^{2+}, \mathrm{Mg}^{2+}, \mathrm{pH} 7.2\right)$ and incubated for 15 minutes at RT. At the end of the incubation period, $100 \mu \mathrm{L}$ of each sample was cytospin centrifuged by for 5 minutes at 700 $\mathrm{rpm}$ on microscopic slides. Following centrifugation, the slides were washed three times for 5 minutes at RT with PBS (w/o Ca $\left.{ }^{2+}, \mathrm{Mg}^{2+}, \mathrm{pH} 7.2\right)$ and stored at $-20^{\circ} \mathrm{C}$. The cells were treated with permeability buffer (0.1 \% Triton-X in PBS and BSA $2 \%$ ) for 10 minutes at RT in a humid chamber, and cells were then washed twice with $50 \mu \mathrm{L}$ PBS for 10 minutes at RT. Platelets were stained for a-tubulin (mouse antihuman a-tubulin IgG, Sigma-Aldrich, St. Louis, Missouri, USA) at RT for at least one hour, washed again twice with $50 \mu \mathrm{L}$ PBS and then incubated with $50 \mu \mathrm{L}$ secondary donkey anti-mouse IgG Alexa Flour 568 
(Abcam, Cambridge, UK) for one hour at RT, incubated with $50 \mu \mathrm{L}$ of phalloidin ATTO 488 solution (1:200; ATTO-TEC GmbH, Siegen, Germany) for further 30 minutes at RT in the dark and then washed twice with PBS. Fluorescence microscopy was performed on a Leica SP5 confocal laser scanning microscope (Leica Microsystems, Wetzlar, Germany) equipped with HCX PL APO lambda blue 40.0x/1.25 OIL UV objective. For image acquisition, fluorescent tags Atto-488 and AlexaFluor-568 were excited by argon $(488 \mathrm{~nm})$ and helium-neon $(\mathrm{HeNe}) 563 \mathrm{~nm}$ laser lines, respectively, selected with an acousto-optic tunable filter (AOTF). Fluorescence emission for Atto-488 and AlexaFluor-568 was collected between 505-515 nm and 550-570 nm on hybrid detectors (HyD) and photomultiplier tubes (PMTs), respectively. Assessment of distribution and organization of marginal band a-tubulin staining was performed by measuring crosssectional line profile ( $5 \mu \mathrm{m}$ length and $1 \mu \mathrm{m}$ width) of non-saturated grayscale fluorescence intensities (pixel values) of immunofluorescent probes across individual platelets in confocal images using Leica Application Suite X (Version 3.7.1, Leica Microsystems, Wetzlar, Germany). Data were plotted using GraphPad Prism version 8.0.0 for Windows, (GraphPad Software, San Diego, California USA). For each storage condition, the microscopic images of at least 10 single platelets were analyzed. In addition, whole blood spiked with platelets from stored PC was also used to prepare blood smears, which were stained as described above. Here, an Olympus BX 40 microscope with UPlanSApo 60x/1.35 Oil objective was used with software cellSensStandard (Imaging Software cellSens, Olympus Corporation, Tokyo, Japan).

\section{Desialylation of stored platelets}

To evaluate the effect of $\mathrm{Mg}$ addition on desialylation of platelets during storage at $4{ }^{\circ} \mathrm{C}$ we determined the binding of fluorescein isothiocyanate (FITC) labeled Erythrina cristagalli lectin (ECL) and Ricinus communis lectin agglutinin (RCA) to platelet surface glycoproteins of RT and cold stored platelets with or without Mg2+ addition. PC was adjusted to a cell count of $300,000 / \mu \mathrm{L}$ and labeled by CD61-

AlexaFluore647 platelet marker (Biolegend, USA). FITC labeled RCA and ECL were added (1 $\mu \mathrm{L}$ 1:500 RCA or 1:250 ECL in SSP+, Biozol, USA) and incubated in the dark for $20 \mathrm{~min}$. After that $200 \mu \mathrm{LSSP}+$ was added, and the samples were washed $(650 \mathrm{xg}, 7 \mathrm{~min})$. The binding of ECL and RCA was analyzed using an FC500 flow cytometer (Beckman Coulter, USA). As a positive control, sialidase (neuraminidase, Sigma Aldrich, USA) was used.

\section{Declarations}

\section{Acknowledgment}

We thank Doreen Biedenweg, Jessica Fuhrmann and Julia Klauke for excellent technical support. 00 gratefully acknowledges support from the German Ministry of Education and Research (ZIK grant to 00 under grant agreement: 03Z22CN11) and from the German Centre of Cardiovascular Research (Postdoc Start-up Grant to 00 under grant agreement: 81X3400107). Funded by the Deutsche Forschungsgemeinschaft (DFG, German Research Foundation) - Project number 374031971 - TRR 240 to $\mathrm{OO}$ and RP.

\section{Author Contribution}


KA and AG conceived the project, developed the experimental setup, and wrote the manuscript. KA and $\mathrm{OO}$ designed and performed all RT-DC experiments. RP designed and performed the fluorescence microscopy experiments and wrote the manuscript. JW, MU and KA achieved the platelet concentrate experiments. All authors contributed to editing and revision the manuscript.

\section{Competing interests statement}

$\mathrm{OO}$ is co-founder of Zellmechanik Dresden $\mathrm{GmbH}$, distributing real-time deformability cytometry. All other authors do not report a conflict of interest.

\section{Data availability}

The datasets generated during and/or analysed during the current study are available from the corresponding author on reasonable request. All data generated or analysed during this study are included in this published article (and its Supplementary Information files).

\section{References}

1 Getz, T. M. Physiology of cold-stored platelets. Transfusion and apheresis science : official journal of the World Apheresis Association : official journal of the European Society for Haemapheresis 58, 12-15, (2019).

2 Marini, I. et al. Cold storage of platelets in additive solution: the impact of residual plasma in apheresis platelet concentrates. Haematologica 104, 207-214, (2019).

3 Wood, B., Padula, M. P., Marks, D. C. \& Johnson, L. Refrigerated storage of platelets initiates changes in platelet surface marker expression and localization of intracellular proteins. Transfusion $\mathbf{5 6}$, 2548-2559, (2016).

4 Hoffmeister, K. M. et al. The clearance mechanism of chilled blood platelets. Cell 112, 87-97, (2003).

5 Rumjantseva, V. \& Hoffmeister, K. M. Novel and unexpected clearance mechanisms for cold platelets. Transfusion and apheresis science : official journal of the World Apheresis Association : official journal of the European Society for Haemapheresis 42, 63-70, (2010).

6 Bode, A. P. \& Knupp, C. L. Effect of cold storage on platelet glycoprotein lb and vesiculation. Transfusion 34, 690-696, (1994).

7 Bergmeier, W. et al. Metalloproteinase inhibitors improve the recovery and hemostatic function of in vitro-aged or -injured mouse platelets. Blood 102, 4229-4235, (2003).

$8 \quad \mathrm{Li}$, Y. et al. Sialylation on O-glycans protects platelets from clearance by liver Kupffer cells. Proceedings of the National Academy of Sciences of the United States of America 114, 8360-8365, 
(2017).

9 Sorensen, A. L. et al. Role of sialic acid for platelet life span: exposure of beta-galactose results in the rapid clearance of platelets from the circulation by asialoglycoprotein receptor-expressing liver macrophages and hepatocytes. Blood 114, 1645-1654, (2009).

10 Oliver, A. E., Tablin, F., Walker, N. J. \& Crowe, J. H. The internal calcium concentration of human platelets increases during chilling. Biochimica et biophysica acta 1416, 349-360, (1999).

11 Kuchay, S. M. \& Chishti, A. H. Calpain-mediated regulation of platelet signaling pathways. Current opinion in hematology 14, 249-254, (2007).

12 Stritt, S. et al. Defects in TRPM7 channel function deregulate thrombopoiesis through altered cellular Mg(2+) homeostasis and cytoskeletal architecture. 7, 11097, (2016).

13 Gotru, S. K. et al. TRPM7 Kinase Controls Calcium Responses in Arterial Thrombosis and Stroke in Mice. Arteriosclerosis, thrombosis, and vascular biology 38, 344-352, (2018).

14 Ngo, A. T. P., McCarty, O. J. T. \& Aslan, J. E. TRPing out Platelet Calcium: TRPM7 (Transient Receptor Potential Melastatin-Like 7) Modulates Calcium Mobilization and Platelet Function via Phospholipase C Interactions. Arteriosclerosis, thrombosis, and vascular biology 38, 285-286, (2018).

15 Sachs, L., Denker, C., Greinacher, A. \& Palankar, R. Quantifying single-platelet biomechanics: An outsider's guide to biophysical methods and recent advances. Research and practice in thrombosis and haemostasis 4, 386-401, (2020).

16 Guzniczak, E. et al. High-throughput assessment of mechanical properties of stem cell derived red blood cells, toward cellular downstream processing. Scientific reports 7, 14457, (2017).

17 Otto, O. et al. Real-time deformability cytometry: on-the-fly cell mechanical phenotyping. Nature methods 12, 199-202, 194 p following 202, (2015).

18 Toepfner, N., Herold, C., Otto, O. \& Rosendahl, P. Detection of human disease conditions by singlecell morpho-rheological phenotyping of blood. eLife 7, (2018).

19 Xavier, M. et al. Mechanical phenotyping of primary human skeletal stem cells in heterogeneous populations by real-time deformability cytometry. Integrative biology : quantitative biosciences from nano to macro 8, 616-623, (2016).

20 Swenson, A. M. et al. Magnesium modulates actin binding and ADP release in myosin motors. The Journal of biological chemistry 289, 23977-23991, (2014).

21 Braun, A., Vogtle, T., Varga-Szabo, D. \& Nieswandt, B. STIM and Orai in hemostasis and thrombosis. Frontiers in bioscience (Landmark edition) 16, 2144-2160, (2011). 
22 Varga-Szabo, D., Braun, A. \& Nieswandt, B. Calcium signaling in platelets. Journal of thrombosis and haemostasis : JTH7, 1057-1066, (2009).

23 Aurich, K. et al. Label-free on chip quality assessment of cellular blood products using real-time deformability cytometry. Lab on a chip 20, 2306-2316, (2020).

24 Hansen, C. E., Qiu, Y., McCarty, O. J. T. \& Lam, W. A. Platelet Mechanotransduction. Annual review of biomedical engineering 20, 253-275, (2018).

25 Chen, W. et al. Refrigeration-Induced Binding of von Willebrand Factor Facilitates Fast Clearance of Refrigerated Platelets. Arteriosclerosis, thrombosis, and vascular biology 37, 2271-2279, (2017).

26 Bachnas, M. A., Akbar, M. I. A., Dachlan, E. G. \& Dekker, G. The role of magnesium sulfate (MgSO(4)) in fetal neuroprotection. The journal of maternal-fetal \& neonatal medicine : the official journal of the European Association of Perinatal Medicine, the Federation of Asia and Oceania Perinatal Societies, the International Society of Perinatal Obstet, 1-13, (2019).

27 Tangvoraphonkchai, K. \& Davenport, A. Magnesium and Cardiovascular Disease. Advances in chronic kidney disease 25, 251-260, (2018).

28 Marques, B. et al. Effects of Oral Magnesium Supplementation on Vascular Function: A Systematic Review and Meta-analysis of Randomized Controlled Trials. (2019).

29 Liu, M., Yang, H. \& Mao, Y. Magnesium and liver disease. Annals of translational medicine 7, 578, (2019).

30 Meledeo, M. A., Campbell, J. E., Rodriguez, A. C., Valenciana, M. V. \& Cap, A. P. Both acute delivery of and storage with magnesium sulfate promote cold-stored platelet aggregation and coagulation function. The journal of trauma and acute care surgery 79, S139-145, (2015).

31 Diedrich, B. et al. In vitro and in vivo effects of potassium and magnesium on storage up to 7 days of apheresis platelet concentrates in platelet additive solution. Vox sanguinis $\mathbf{9 4 ,}$ 96-102, (2008).

32 Shanwell, A., Falker, C. \& Gulliksson, H. Storage of platelets in additive solutions: the effects of magnesium and potassium on the release of RANTES, beta-thromboglobulin, platelet factor 4 and interleukin-7, during storage. Vox sanguinis 85, 206-212, (2003).

33 Bynum, J. A. et al. Evaluation of adenosine, lidocaine, and magnesium for enhancement of platelet function during storage. The journal of trauma and acute care surgery 83, S9-s15, (2017).

34 Getz, T. M., Turgeon, A. \& Wagner, S. J. Sodium citrate contributes to the platelet storage lesion. Transfusion 59, 2103-2112, (2019). 
35 Jansen, A. J. et al. Desialylation accelerates platelet clearance after refrigeration and initiates GPIba metalloproteinase-mediated cleavage in mice. Blood 119, 1263-1273, (2012).

36 Shiri, R., Yari, F., Ahmadinejad, M., Vaeli, S. \& Tabatabaei, M. R. The caspase-3 inhibitor (peptide Z-DEVD-FMK) affects the survival and function of platelets in platelet concentrate during storage. Blood research 49, 49-53, (2014).

37 Rock, G. \& Figueredo, A. Metabolic changes during platelet storage. Transfusion 16, 571-579, (1976).

\section{Table}

Table 1. Cell counts before and after filtration of whole blood by LEUCOFLEX® LXT filter (mean \pm standard deviation, $\mathrm{n}=3$ )

\begin{tabular}{|lll|}
\hline Cell count & Whole blood before filtration & Whole blood after filtration \\
\hline Red blood cell $\left(\times 10^{12} / \mathrm{L}\right)$ & $5.3 \pm 0.3$ & $6.5 \pm 2.2$ \\
\hline Leukocytes $\left(\times 10^{9} / \mathrm{L}\right)$ & $5.8 \pm 1.1$ & 0 \\
\hline Platelets $\left(\times 10^{9} / \mathrm{L}\right)$ & $247.3 \pm 34.6$ & $1.9 \pm 0.2$ \\
\hline
\end{tabular}

Table 2. Storage conditions of platelet concentrates in PAS plus 30\% plasma

\begin{tabular}{|llll|}
\hline & $\begin{array}{l}\text { Storage } \\
\text { temperature }\end{array}$ & $\begin{array}{l}\text { Added magnesium concentration } \\
(\mathrm{mM})\end{array}$ & $\begin{array}{l}\text { Final magnesium concentration in PC } \\
(\mathrm{mM})\end{array}$ \\
\hline $\begin{array}{l}\text { Room } \\
\text { temperature }\end{array}$ & 0 & 2 \\
\hline 2 & $4{ }^{\circ} \mathrm{C}$ & 0 & 2 \\
\hline 3 & $4{ }^{\circ} \mathrm{C}$ & 2 & 4 \\
\hline 4 & $4{ }^{\circ} \mathrm{C}$ & 4 & 6 \\
\hline 5 & $4{ }^{\circ} \mathrm{C}$ & 6 & 8 \\
\hline 6 & $4{ }^{\circ} \mathrm{C}$ & 8 & 10 \\
\hline
\end{tabular}

\section{Figures}


A

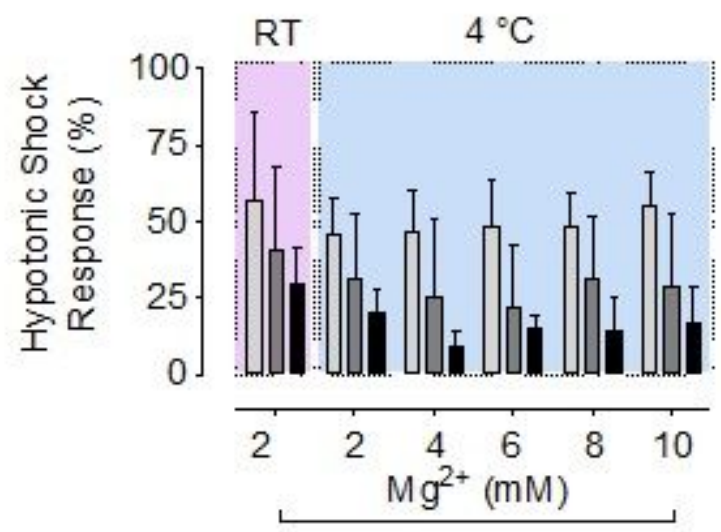

B

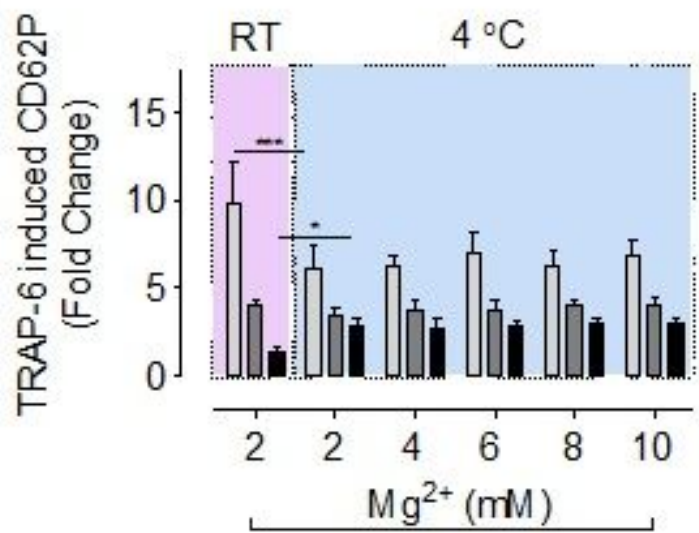

C

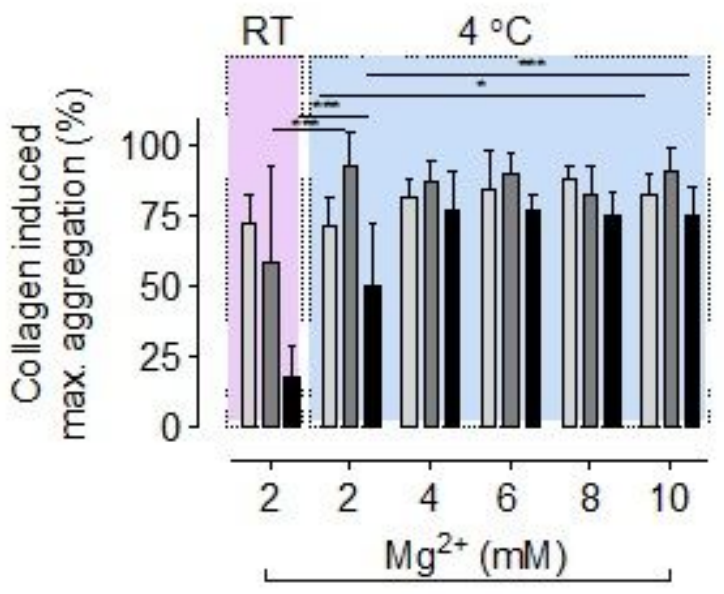

D

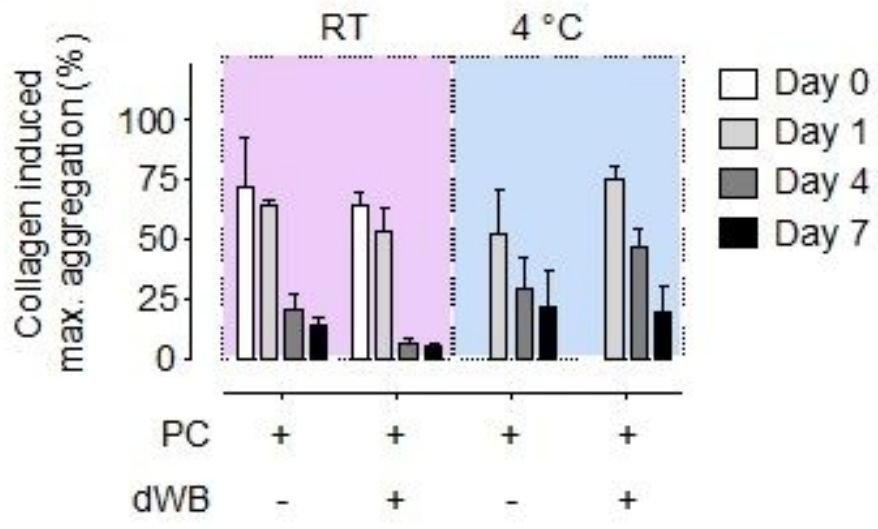

\section{Figure 1}

(A) Hypotonic shock response, (B) fold increase of CD62P mean fluorescence intensity after $20 \mu \mathrm{M}$ TRAP6 addition in comparison to buffer-control, and (C) maximum aggregation after $8 \mu \mathrm{g} / \mathrm{mL}$ collagen I addition to platelets from PC stored at RT $+2 \mathrm{mM} \mathrm{Mg} 2+, 4^{\circ} \mathrm{C}+2,4,6,8$ or $10 \mathrm{mM} \mathrm{Mg} 2+(\mathrm{n}=6$, mean $\pm S D$ ). (D) Maximum aggregation after $8 \mu \mathrm{g} / \mathrm{mL}$ collagen I addition to platelets from PC stored at RT or $4{ }^{\circ} \mathrm{C}$ either subsequently added to platelet depleted, tempered whole blood (dWB) or not $(n=3$, mean $\pm S D) . P C=$ platelet concentrate, $R T=$ room temperature, $M g 2+=$ magnesium, $S D=$ standard deviation, ${ }^{*} \mathrm{p}<0.05, * * * \mathrm{p}<0.001$ 
A
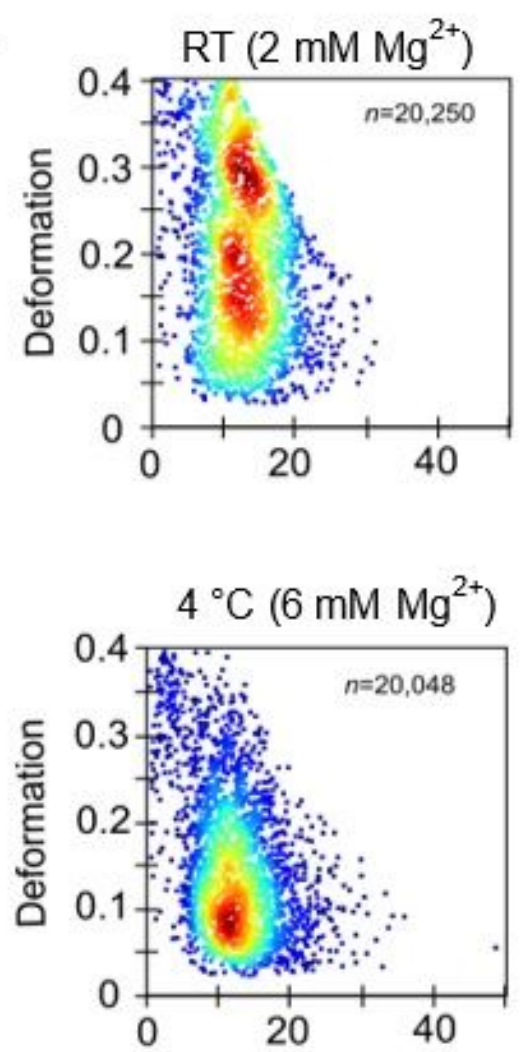

B
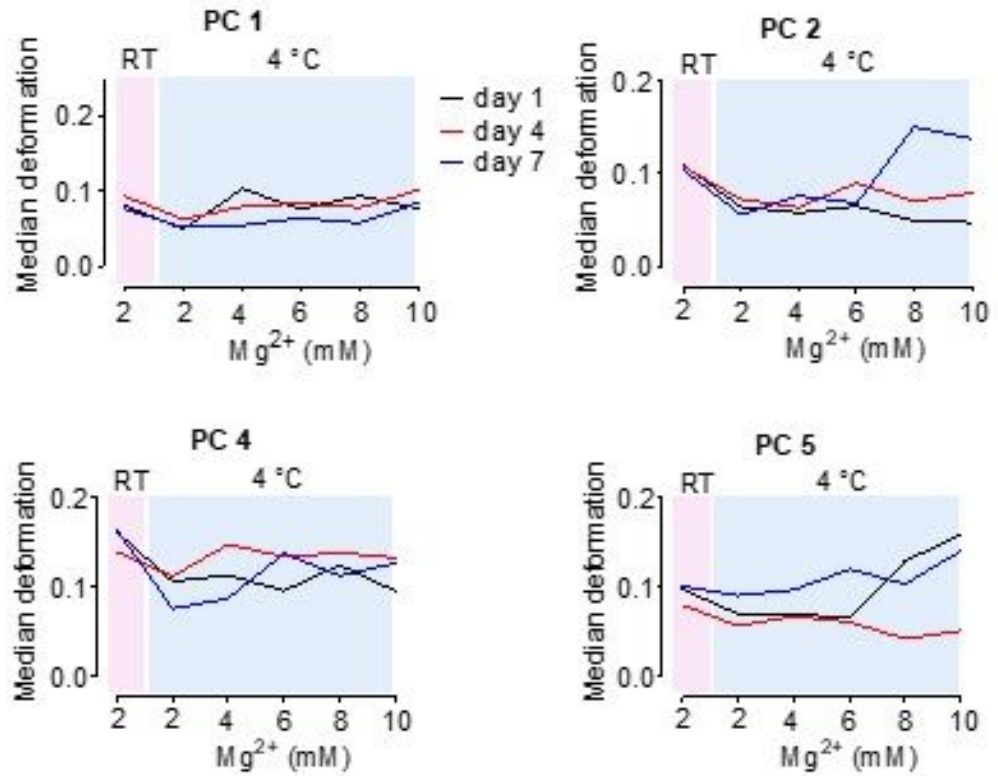
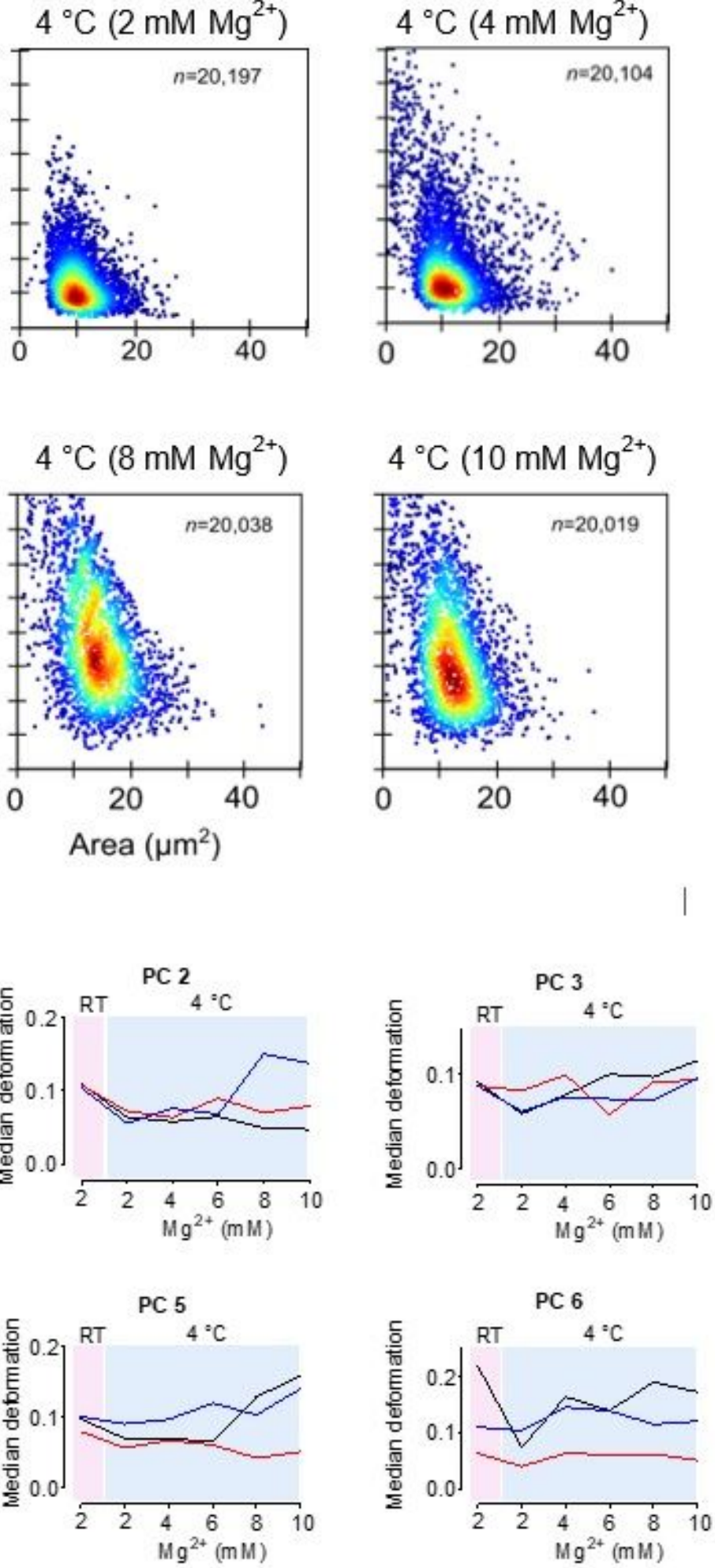

\section{Figure 2}

(A) Deformation vs cell area scatterplots determined by RT-DC of platelets from one PC stored for 7 days under different conditions at $\mathrm{RT}+2 \mathrm{mM} \mathrm{Mg} 2+, 4{ }^{\circ} \mathrm{C}+2,4,6,8$ or $10 \mathrm{mM} \mathrm{Mg} 2+$. (B) Median deformation of platelets in platelet concentrates $(\mathrm{PC}, \mathrm{n}=6)$ for each magnesium concentration and storage temperature are given for day 1 (black), day 4 (red) and day 7 (blue), $n \geq 20,000$ platelets. RT=room temperature, $\mathrm{Mg} 2+=$ magnesium. 

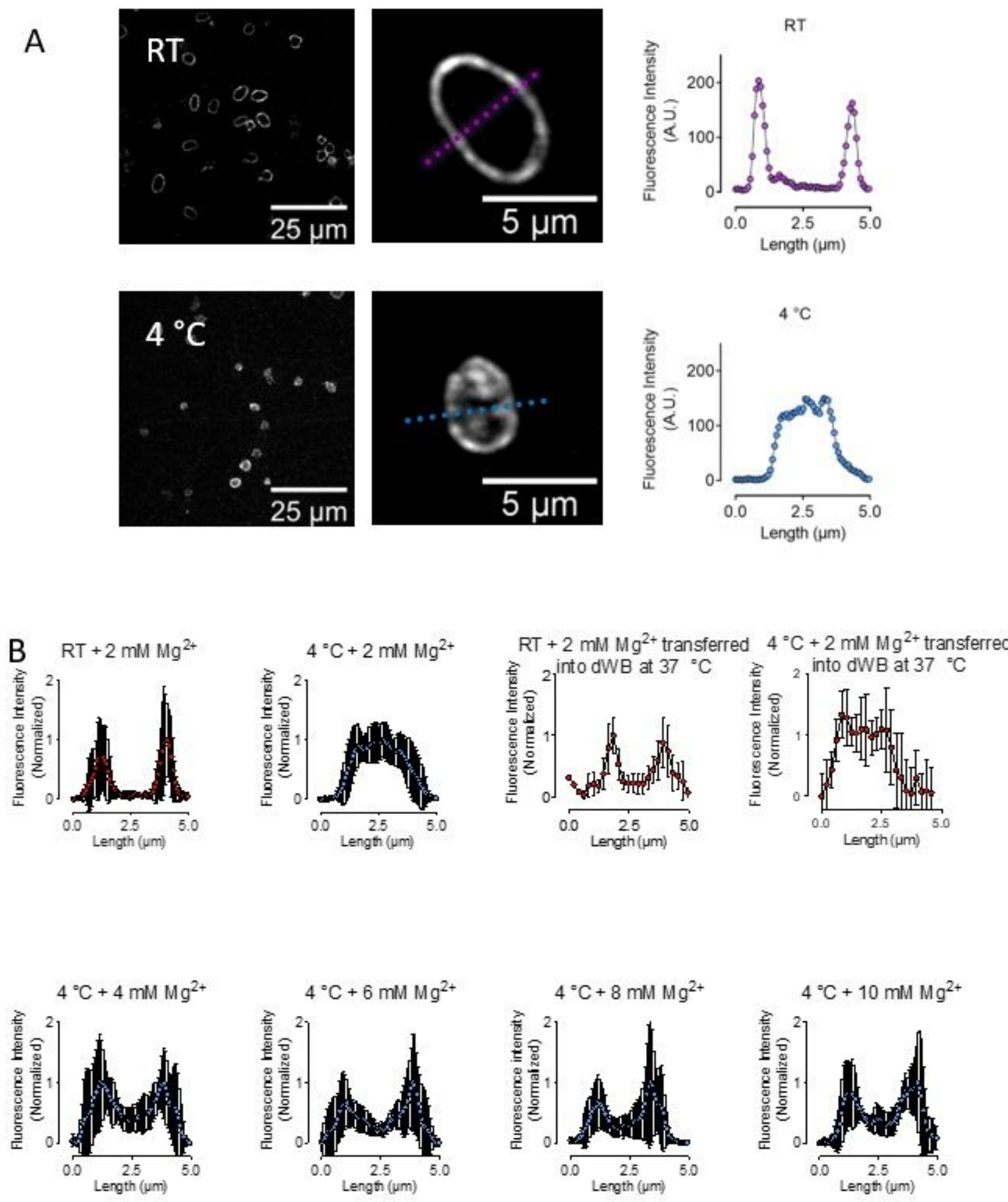

\section{Figure 3}

(A) Fluorescence image and intensity of stained a-tubulin along an axis of the platelet cross-section of platelets from PC stored at RT or $4{ }^{\circ} \mathrm{C}$. (B) Normalized fluorescence intensity of stained a-tubulin along an axis of the platelet cross-section of platelets stored for $24 \mathrm{~h}$ under different conditions ( $n=10, m e a n \pm S D)$. a-tubulin was stained by mouse anti-human a-tubulin lgG + secondary donkey anti-mouse lgG Alexa Flour 568. RT=room temperature, Mg2+=magnesium, dWB=platelet depleted whole blood 


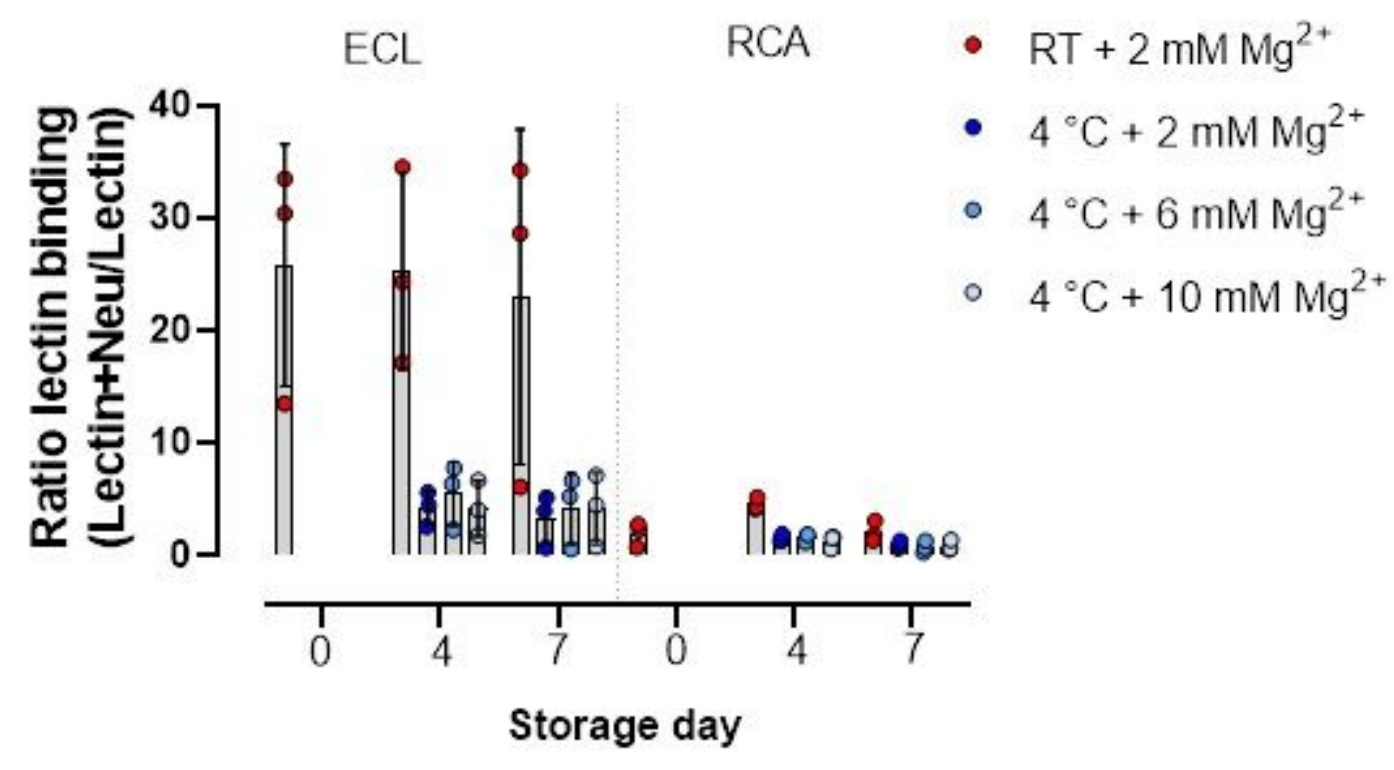

Figure 4

Impact of Mg2+ addition to desialylation of platelets. Binding of fluorescently labeled Erythrina cristagalli lectin (ECL) and Ricinus communis agglutinin (RCA) to platelet surface glycoproteins of RT and coldstored platelets with or without $\mathrm{Mg} 2+$ in the presence and absence of sialidase during 7 days storage. $\mathrm{RT}=$ room temperature, $\mathrm{Mg} 2+=$ magnesium. $\mathrm{n}=3$, mean+standard deviation.

\section{Supplementary Files}

This is a list of supplementary files associated with this preprint. Click to download.

- SupplementaryFigures.pdf 